\title{
Technical Diagnostics of Ventilation Units for Energy Efficiency and Safety of Operation
}

\author{
Evgeny Kuzin ${ }^{* 1}$, Vitaliy Shahmanov ${ }^{1}$, and Dmitriy Dubinkin ${ }^{1}$ \\ ${ }^{1}$ Prokopievsk branch of T. F. Gorbachev Kuzbass State Technical University, 653039, 19a \\ Nogradskaya str., Prokopievsk, Russia
}

\begin{abstract}
The article considers the questions of application of technical diagnostics fan installations methods for providing safe operation, the system of the technical maintenance improvement and repair. Due to the fact that one of the most important aspects in fan operation in mining is energy efficiency and energy saving, the lack of the data in the control of the level in vibration of stationary sensors is shown. The necessity of taking into account the geometric parameters of the intake channel has been shown, and also the necessity of creation of the reference masks for the assessment of technical condition and energy efficiency when operating fan installations in mining. The results of technical diagnostics of the main fans using the methods of vibration diagnostics are provided. Aspects of vibration at characteristic points are shown. The necessity for further accumulation of data characterizing vibration for adjustment of the reference masks and more accurate detection of defects and deviations from the energy-efficient mode of operation of the fan installations is given.
\end{abstract}

\section{Introduction}

Fan installation in mining operations provide ventilation of the main and auxiliary mine workings, and also used for preliminary degassing of coal seams. Primarily, personnel safety depends on the safe operation of installations of ventilation and degassing of negative consequences caused by the release of methane in underground mines.

All ventilation systems of coal mines are reserved and supplied with stationary vibration temperature and performance sensors. This controls the working of the ventilation system, but not its energy efficiency.

Due to the continuous growth of energy tariffs, as well as in the framework of the «A policy framework for climate and energy in the period from 2020 to 2030» and the International standard ISO $50001[1,2]$, it is very important not only to reduce energy losses, but also to provide efficient service for the maintenance and repair of equipment of mining enterprises. Energy saving is more beneficial than generation capacity, because the costs of saving $1 \mathrm{~kW}$ of power costs four to five times cheaper than the cost of a newly commissioned $1 \mathrm{~kW}$ of power, depending on the remoteness of the enterprise from generating plants.

\footnotetext{
*Corresponding author: kuzinevgen@gmail.com
} 


\section{Materials and methods}

Based on the results of the measurements only the overall level of vibration (for example, in a wide range of 2-1000 Hz) changes in the condition of rotating machinery to a condition in which increasing the amplitude of certain harmonics will reach the level of the component with the largest amplitude (usually at a frequency of rotation of the rotor) can not be detected [3]. This condition can be evaluated as satisfactory (exp limited time), in this case the energy saving in the operation of this equipment is not taken into account [4].

For detailing the defects the limits on vibration level for individual spectral components (reference masks) that is associated with different levels of risks of emergency failure of equipment from various defects are introduced. The method of using the reference masks allows you to not only to evaluate, but also to predict the change in the condition of the equipment $[5,6]$. In addition, for each fan size, it is advisable to create your own reference mask, as it influences not only frequency of rotation of the rotor, but the number of vanes (blades) of the fan. It is proposed to use the method of reference masks to assess the efficiency of the fan. Defects such as imbalance and misalignment leads to increasing mechanical losses, therefore to a waste of energy.

Much attention is paid to the energy saving in the adjustment of performance, it is also known that the efficiency of axial fans is influenced by the geometric dimensions of the duct, the distance between the impeller and diffuser and other aspects [7, 8].

Thus, in this work the selected method of construction of the reference masks, to ensure safe operation and evaluation of energy efficiency when the fan has been chosen.

\section{Results and Discussion}

During the operation of the fan $2 \mathrm{VDK}-32 / 2$ stationary system of vibration diagnostics the repeated exceeding of the maximum allowable level of vibrations at $11.2 \mathrm{~mm} / \mathrm{c}$ has been noticed. It has decided to conduct the diagnostics in the manual mode. Point measurements of vibration are shown in Fig. 1. and the total vibration is shown in table. 1

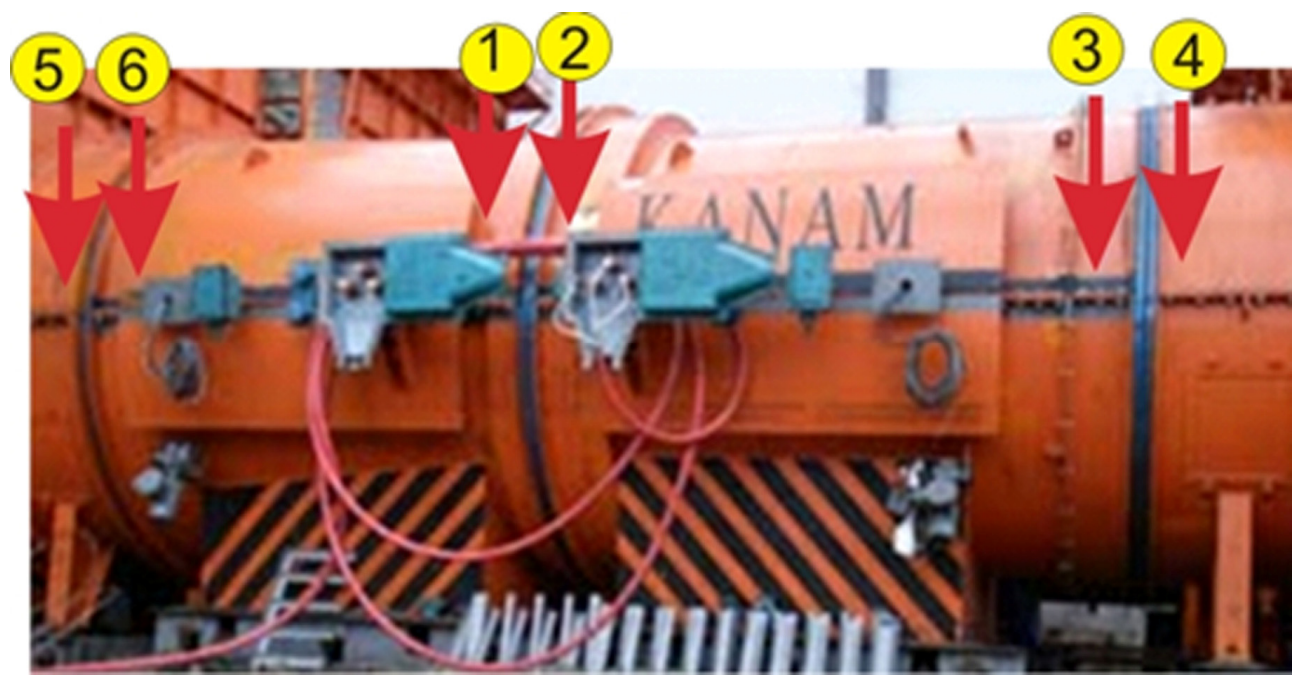

Fig. 1. The scheme of measurements of vibration on the fan $2 \mathrm{VDK}-32 / 2$

Table 1. The overall level of vibration in the range $2-1000 \mathrm{~Hz}$ 


\begin{tabular}{|c|c|c|c|c|c|}
\hline $\begin{array}{c}\text { Measuring } \\
\text { point }\end{array}$ & $\begin{array}{c}\text { RMS, } \\
\mathbf{m m} / \mathbf{s}\end{array}$ & $\begin{array}{c}\text { Measuring } \\
\text { point }\end{array}$ & $\begin{array}{c}\text { RMS, } \\
\mathbf{m m} / \mathbf{s}\end{array}$ & $\begin{array}{c}\text { Measuring } \\
\text { point }\end{array}$ & $\begin{array}{c}\text { RMS, } \\
\mathbf{m m} / \mathbf{s}\end{array}$ \\
\hline $1 \mathrm{~V}$ & 1,53 & $3 \mathrm{~V}$ & 2,80 & $5 \mathrm{~V}$ & 1,68 \\
\hline $1 \mathrm{H}$ & 4,16 & $3 \mathrm{H}$ & 5,85 & $5 \mathrm{H}$ & 4,30 \\
\hline $1 \mathrm{~A}$ & 2,06 & $3 \mathrm{~A}$ & 2,98 & $5 \mathrm{~A}$ & 1,31 \\
\hline $2 \mathrm{~V}$ & 3,75 & $4 \mathrm{~V}$ & 2,04 & $6 \mathrm{~V}$ & 2,49 \\
\hline $2 \mathrm{H}$ & 5,69 & $4 \mathrm{H}$ & 3,68 & $6 \mathrm{H}$ & 4,25 \\
\hline $2 \mathrm{~A}$ & 7,35 & $4 \mathrm{~A}$ & 1,95 & $6 \mathrm{~A}$ & 2,03 \\
\hline
\end{tabular}

Analysis of the data in the table shows that at the point $2 \mathrm{~A}$ overall vibration level reaches a warning. The results of detailed analysis show the following: current frequency of the rotor

$$
f_{r}=\frac{n}{60}=\frac{750}{60}=12,5 \mathrm{~Hz}
$$

where $\mathrm{n}=750 \mathrm{rpm}$, the rotational speed of the rotor of the motor.

Fig. 2)

Noticed some imbalance of the fan impeller in the General level within zone A (see

The frequency of the flow on the blades of stage 1 (the number of blades of stage 1)

$$
f_{l 1}=f_{r} \cdot z_{1}=12,5 \cdot 15=187,5 \mathrm{~Hz}
$$

The frequency of the flow on the blades 2 of the degree (the number of blades 2 stages)

$$
f_{l 2}=f_{r} \cdot z_{2}=12,5 \cdot 11=137,5 \mathrm{~Hz}
$$

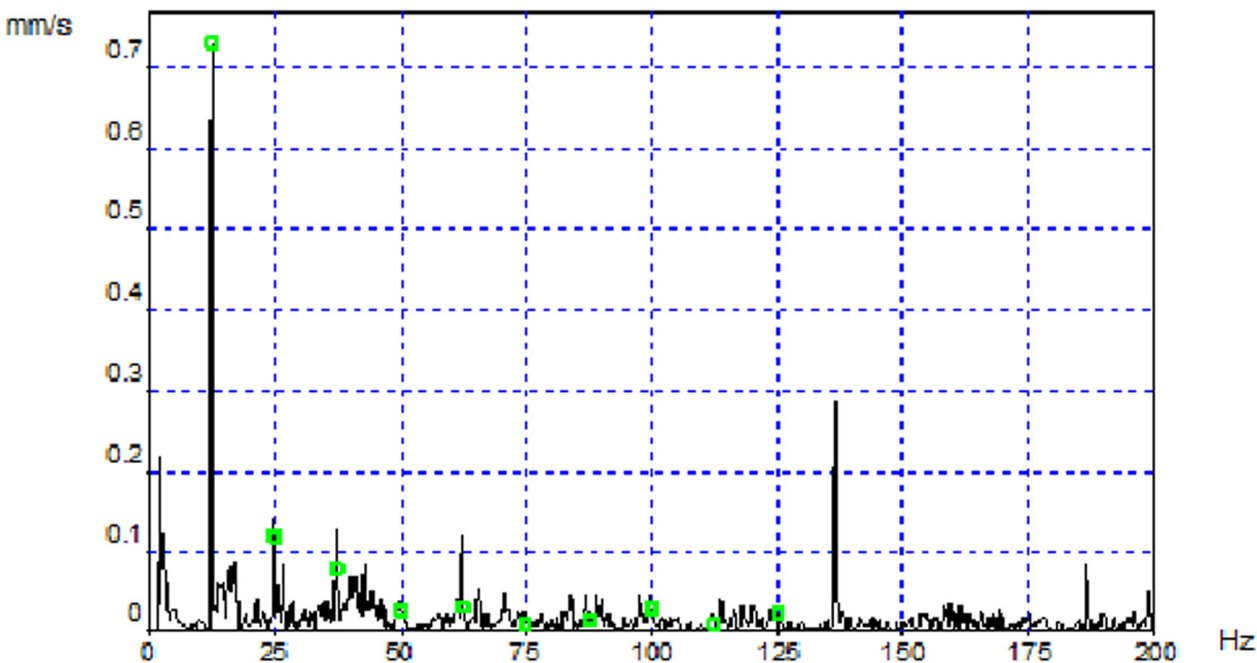

Fig. 2. A vibration spectrum at point 1V stands still from 23.06.2017

This fan has some features, such as the second fan stage 2 VDK-32/2 is mounted coaxially of the first stage with the technological gap between the end planes of the runners. In order to avoid the use of guide vanes and thereby to increase the efficiency of the fan rotation direction of impellers they are made opposite $[9,10]$.

The frequency of collision of flows in the transition to the second stage (taken from a real frequency in the spectra of Fig. 3) 


$$
f_{l 1-2}=f_{l 1}+f_{l 2}=186,2+136,2=322 \mathrm{~Hz}
$$

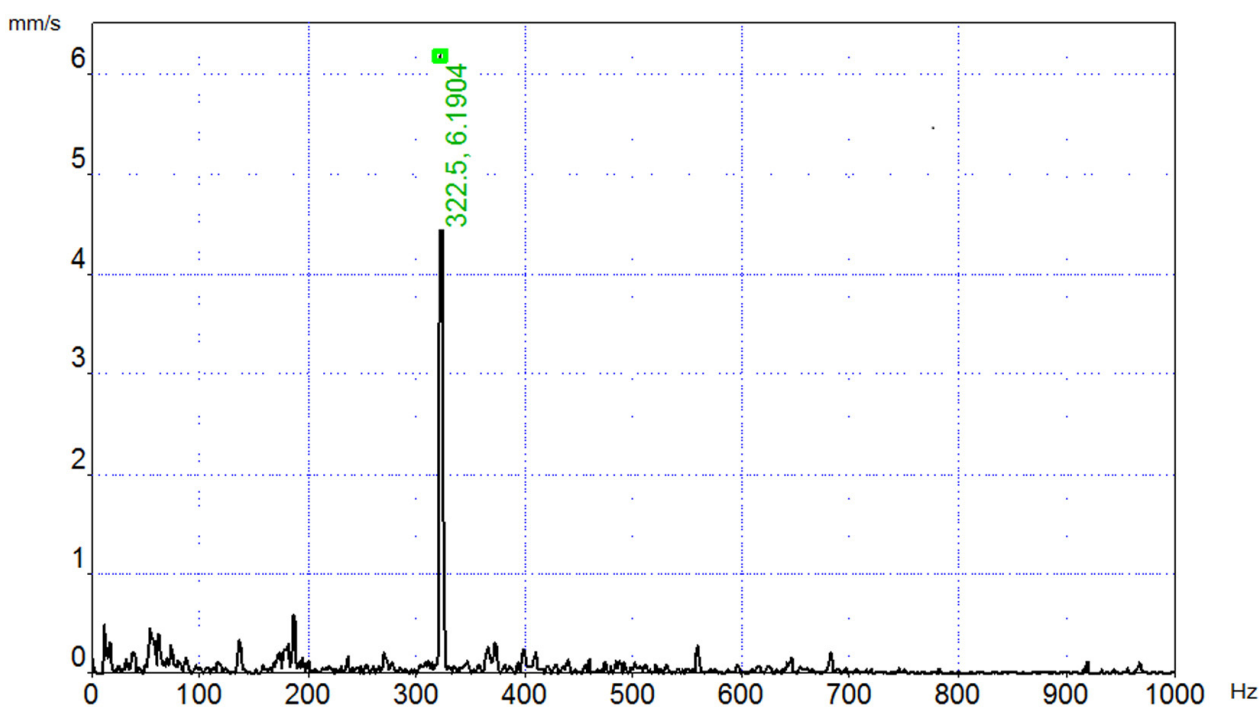

Fig. 3. A vibration spectrum at the point $2 \mathrm{~A}$ stands still 23.06.2017

To improve the energy efficiency by reducing energy losses on the guide apparatus between the motor and the impeller counter-rotating wheels direct the flow of air from one to another, is confirmed by studies [10 - 13]. For stabilization of the flow in a ventilation pipe a mounted stabilizer has been assembled.

The reference spectra are compiled for each of the characteristic frequencies of the fan, according to the diagnostics carried out after running-in (about 1000 - 1500 hours) for the characteristic points. Compared to the reference spectrum reference masks are generated.

The reference masks designed for this fan, (shown in Fig. 4 to point 2) have warning and alarm levels.

Thus, a relatively high level of vibration is caused by the stall of the vanes of the first wheel when the transition to the second one and does not affect the normal operation of the fan and the vibration of the bearing supports. However, the exceeding of the warning level for the frequency of threads collision means the reducing of the fan efficiency. It is advisable to check the air channel to change the geometric parameters, seals, air suction, etc. 


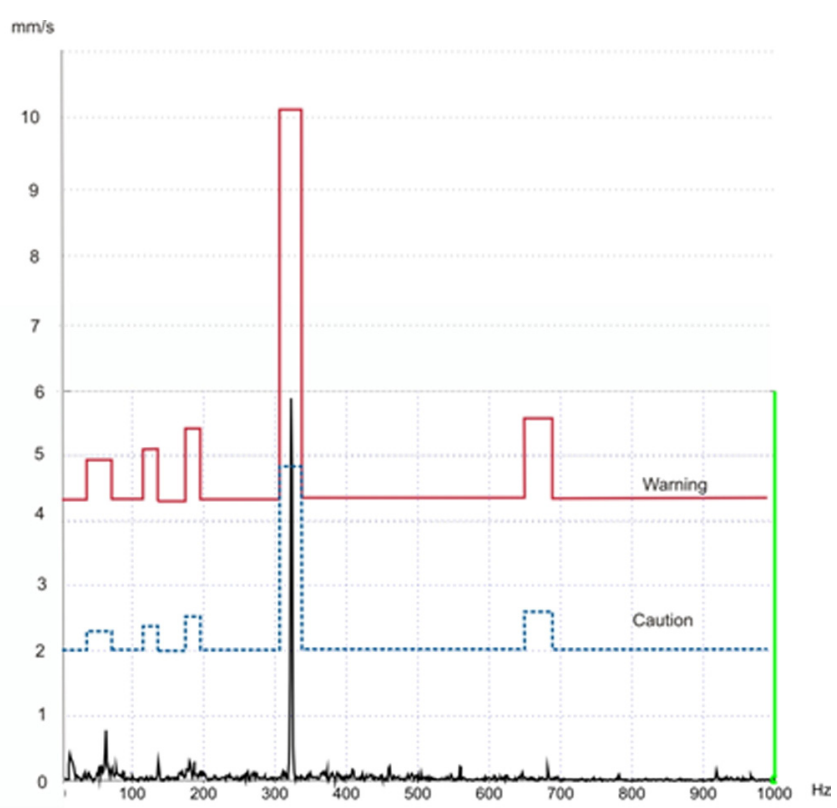

Fig. 4. The reference mask to a point $2 \mathrm{~A}$

\section{Conclusion}

When carrying out the technical diagnostics after comparing the current spectra with the reference it is possible to evaluate the technical condition of the fan to the area of warning as efficient, in excess of the individual frequencies as limited functional, but not energetically efficient. In case of exceeding the level of anxiety, the spectra of vibration must be analyzed. A detailed analysis allows to evaluate the condition of motor bearings and impeller, the blades of the first and second stages, as well as the occurrence of the flow separation due to the irregularities of the aerodynamic characteristics of the duct.

The use of a sufficient number of spectral masks requires a long process of accumulation of experimental data. It makes the method time consuming. However, thanks to the subsequent use of masks the diagnosis will be performed quickly and reliably.

\section{References}

1. Energy management systems - Requirements with guidance for use. ISO 50001 (2011)

2. A policy framework for climate and energy in the period from 2020 to 2030

3. ISO 10816-1: Mechanical vibration - Evaluation of machine vibration by measurements on non-rotating parts - Part 1

4. B. Gerike, I. Panachev, E. Kuzin, E3S Web of Conferences, 15, 03008 (2017)

5. XiuJun Yang, Procedia Engineering, 166, 32 (2016)

6. Air Pollution and Turbulence. Modeling and Applications, 324 (CRC Press. Boca Ration. London. NewYork, 2010)

7. Xiaohang Jinl, W. M. Mal Eden, W. S. Chowl, M. Pechtl, Prognostics \& System Health Management, 4, 984 (2012) 
8. Shi Lei, Liu Bo, Na Zhenzhe, Wu Xiaoxiong, Lu Xiaofeng. Chinese Journal of Aeronautics, 28:4, 1044 (2015)

9. B. Dobrzynski, H. Saathoff, G. Kosyna, Proceedings of ASME Turbo Expo 2008: power for land, sea and air, 176-182 (2008)

10. Hao Ming L, Ibrahim Hassan. Heat Transfer Engineering, 36:16 (2015)

11. Howard A. Gaberson, Sound \& Vibration, 11 (2013)

12. C. El Ayoubi, WS Ghaly IG Hassan, Journal of Propulsion and Power, 31:2, 543 (2015) 